\title{
NUMERICAL SIMULATION OF WATER CIRCULATION IN A CYLINDRICAL HORIZONTAL THERMAL TANK
}

\begin{abstract}
D. L. Savicki ${ }^{\mathrm{a}}$,
and H. A. Vielmo ${ }^{\text {, }}$,

${ }^{a}$ Federal University of Rio Grande Institute of Mathematics, Statistics and Physics

Av. Itália, km 8, CEP: 96201-900,

Rio Grande, RS, Brasil

darcisavicki@furg.br

${ }^{\mathrm{b}}$ Federal University of Rio Grande Do Sul

Mechanical Engineering Graduate Program

Porto Alegre, RS, Brasil

ABSTRACT

It is carried out a numerical study of the three-dimensional temperature and velocity fields in a cylindrical horizontal thermal tank during the process of water circulation. The numerical simulations were made using an academic Finite Volumes numerical code. This simulation considers that the thermal tank is connected to solar collectors. So, in the tank, the inlet jet temperature is higher than those inside the tank. This study aims to investigate the influence of the inlet jet on thermal stratification. The results show that for the mass flow rate studied, there is no significant variation on thermal stratification.
\end{abstract}

Keywords: solar energy, storage tank, Finite Volumes Method

\section{NOMENCLATURE}

$c_{p} \quad$ specific heat of water, $\mathrm{kJ} / \mathrm{kg} \cdot \mathrm{K}$

$g$ gravitational acceleration, $\mathrm{m} / \mathrm{s}^{2}$

$\mathrm{h}_{\text {ext }} \quad$ external heat transfer coefficient, $W / m^{2} \cdot K$

$k \quad$ thermal conductivity of water, $W / m \cdot K$

$\mathrm{p} \quad$ pressure, $\mathrm{Pa}$

S source term, $W / m^{3}$ for energy equation and $\mathrm{kg} / \mathrm{m}^{2} \cdot \mathrm{s}^{2}$ for momentum equations

T Temperature, ${ }^{\circ} \mathrm{C}$

$\mathrm{t} \quad$ Time, $\mathrm{s}$

$V_{\theta} \quad$ angular velocity component, $\mathrm{m} / \mathrm{s}$

$V_{r} \quad$ radial velocity component, $\mathrm{m} / \mathrm{s}$

$V_{z} \quad$ axial velocity component, $\mathrm{m} / \mathrm{s}$

$\begin{array}{ll} & \text { subscripts } \\ \mathrm{r} & \text { radial direction } \\ \mathrm{z} & \text { axial direction } \\ \text { int } & \text { internal } \\ \text { ext } & \text { external } \\ \text { in } & \text { inlet } \\ \text { out } & \text { outlet } \\ \text { ini } & \text { initial } \\ \infty & \text { free stream }\end{array}$

\section{Greek letters}

$\theta \quad$ angular direction, rad

$\mu \quad$ viscosity, $\mathrm{kg} / \mathrm{m} \cdot \mathrm{s}$

$\rho \quad$ density, $\mathrm{kg} / \mathrm{m}^{3}$

\section{INTRODUCTION}

One of the issues of interest in natural convection is the optimization of the thermal energy storage equipments. An illustrative case is solar water heating systems, where a good performance of the thermal reservoir represents a considerable increase in the global efficiency. In such systems, one of the most desirable characteristics is a high thermal stratification, which is a function of parameters such as the inlet jet velocity and the difference between the inlet and outlet jet temperature (Oliveski, 2003). Thus, for system optimization, an appropriate determination of these parameters is relevant. The maintenance of the thermal stratification is important up to a certain time in the day, leading to a good efficiency in the collectors while the solar irradiation is still intense (Alizadeh, 1999).

In the present work, the numerical simulations of this phenomenon was carried out using an academic code, written in Fortran language, where the Finite Volumes Method, in structured meshes, is implemented to solve the differential equations of energy and momentum, in laminar condition. The TDMA algorithm, with block correction, is employed, and as interpolation scheme the PowerLaw was chosen.

\section{THEORY}

In cylindrical coordinates, for incompressible laminar flow of a Newtonian fluid, and using the Boussinesq approach, the problem is described by the following system of equations:

Continuity Equation:

$\frac{\partial \rho}{\partial t}+\frac{1}{r} \frac{\partial}{\partial r}\left(\rho r V_{r}\right)+\frac{1}{r} \frac{\partial}{\partial \theta}\left(\rho V_{\theta}\right)+\frac{\partial}{\partial z}\left(\rho V_{z}\right)=0$ 
Momentum Equations:

In the angular direction:

$$
\begin{aligned}
& \frac{\partial\left(\rho V_{\theta}\right)}{\partial t}+\frac{1}{r} \frac{\partial\left(\rho V_{\theta} V_{\theta}\right)}{\partial \theta}+\frac{\partial\left(\rho V_{r} V_{\theta}\right)}{\partial r}+\frac{\partial\left(\rho V_{z} V_{\theta}\right)}{\partial z}=-\frac{1}{r} \frac{\partial p}{\partial \theta}+ \\
& \frac{1}{r^{2}} \frac{\partial}{\partial \theta}\left(\mu \frac{\partial V_{\theta}}{\partial \theta}\right)+\frac{1}{r} \frac{\partial}{\partial r}\left(\frac{\partial\left(\mu r V_{\theta}\right)}{\partial r}\right)+\frac{\partial}{\partial z}\left(\mu \frac{\partial V_{\theta}}{\partial z}\right)+S^{V_{\theta}}
\end{aligned}
$$

where

$$
\begin{gathered}
S^{V_{\theta}}=-\frac{\rho V_{r} V_{\theta}}{r}+\frac{2}{r^{2}} \frac{\partial\left(\mu V_{r}\right)}{\partial \theta}-\frac{\mu V_{\theta}}{r^{2}}-\left(\rho-\rho_{\infty}\right) g \operatorname{sen} \theta \\
\text { In the radial direction: } \\
\frac{\partial\left(\rho V_{r}\right)}{\partial t}+\frac{1}{r} \frac{\partial\left(\rho V_{\theta} V_{r}\right)}{\partial \theta}+\frac{\partial\left(\rho V_{r} V_{r}\right)}{\partial r}+\frac{\partial\left(\rho V_{z} V_{r}\right)}{\partial z}=-\frac{\partial p}{\partial r}+ \\
\frac{1}{r^{2}} \frac{\partial}{\partial \theta}\left(\mu \frac{\partial V_{r}}{\partial \theta}\right)+\frac{1}{r} \frac{\partial}{\partial r}\left(\frac{\partial\left(\mu r V_{r}\right)}{\partial r}\right)+\frac{\partial}{\partial z}\left(\mu \frac{\partial V_{r}}{\partial z}\right)+S^{V_{r}}
\end{gathered}
$$

where

$$
\begin{aligned}
S^{V_{r}}= & \frac{\rho V_{\theta}^{2}}{r}-\frac{2}{r^{2}} \frac{\partial}{\partial \theta}\left(\mu V_{\theta}\right)-\frac{\mu V_{r}}{r^{2}}+\left(\rho-\rho_{\infty}\right) g \cos \theta \\
& \text { In the axial direction: } \\
& \frac{\partial\left(\rho V_{z}\right)}{\partial t}+\frac{1}{r} \frac{\partial\left(\rho V_{\theta} V_{z}\right)}{\partial \theta}+\frac{\partial\left(\rho V_{r} V_{z}\right)}{\partial r}+\frac{\partial\left(\rho V_{z} V_{z}\right)}{\partial z}=-\frac{\partial p}{\partial z}+ \\
& \frac{1}{r} \frac{\partial}{\partial r}\left(\mu r \frac{\partial V_{z}}{\partial r}\right)+\frac{1}{r^{2}} \frac{\partial}{\partial \theta}\left(\mu \frac{\partial V_{z}}{\partial \theta}\right)+\frac{\partial}{\partial z}\left(\mu \frac{\partial V_{z}}{\partial z}\right)
\end{aligned}
$$

The initial condition is null velocity for the entire domain. The boundary conditions correspond to null velocity in the external faces and symmetry on the planes $r \theta$ and $r z$. Along the line $r=0$, the boundary conditions

are $V_{\theta}=0 ; V_{r}=0$ and $\frac{\partial V_{z}}{\partial r}=0$.

$$
\begin{aligned}
& \text { Energy Equation: } \\
& \frac{\partial\left(\rho c_{p} T\right)}{\partial t}+\frac{1}{r} \frac{\partial\left(\rho V_{\theta} c_{p} T\right)}{\partial \theta}+\frac{\partial\left(\rho V_{r} c_{p} T\right)}{\partial r}+\frac{\partial\left(\rho V_{z} c_{p} T\right)}{\partial z}= \\
& {\left[\frac{1}{r^{2}} \frac{\partial}{\partial \theta}\left(k \frac{\partial T}{\partial \theta}\right)+\frac{1}{r} \frac{\partial}{\partial r}\left(k r \frac{\partial T}{\partial r}\right)+\frac{\partial}{\partial z}\left(k \frac{\partial T}{\partial z}\right)\right]}
\end{aligned}
$$

As initial condition for the energy equation, the temperature profile is prescribed. For boundary condition symmetry is applied along the line $r=0$ and on the planes $r \theta$ and $r z(\theta=0$ and $\theta=\pi)$. The outer faces of the reservoir are adiabatic.

In this formulation of the math model, the physical properties of the water ( $\rho, \rho_{\infty}, \mu, k$ and $c_{p}$ ) are function of temperature, updated in time through polynomial fit. The evolution of the transient problem is carried out in a fully implicit form. The iterative computation process is applied until it is reached the criterion that the maximum mass flow residue is less than $10^{-5} \mathrm{~kg} / \mathrm{s}$. For energy equation, the relative error to temperature variable was required less than $10^{-5}$. The adopted time step was 0.25 s. These values were obtained through independency mesh tests.

Figure 1 shows an example of the mesh configuration utilized. The actual used mesh is, in reality, more refined, with $75 \times 200 \times 200$ volumes ( $r \theta z$, respectively), so that the border volume resemble a cubic format.

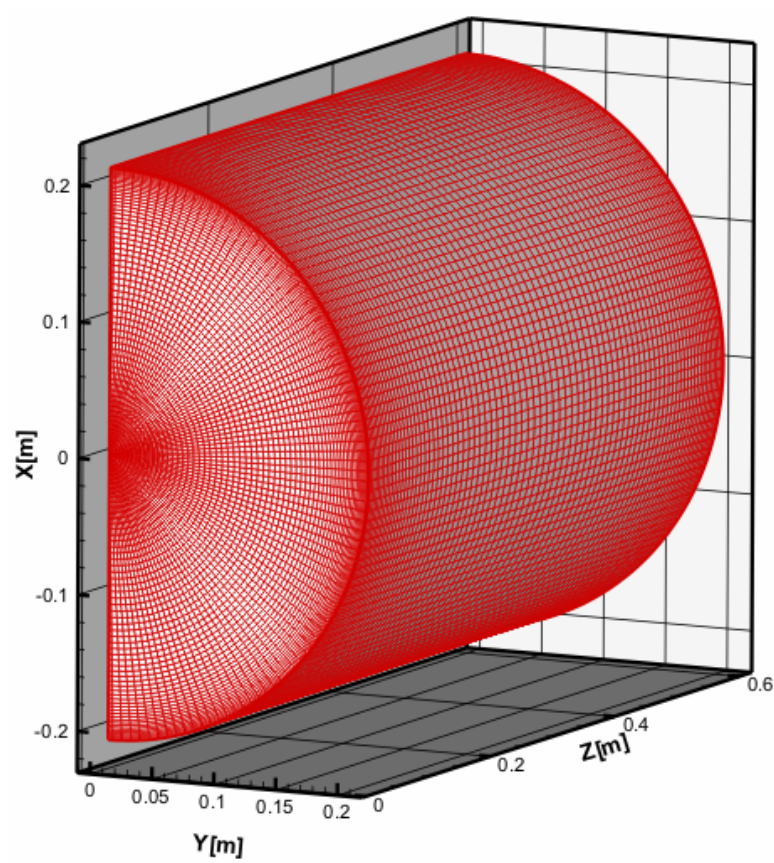

Figure 1. Structured mesh in cylindrical coordinate system for calculating in academic code.

\section{NUMERICAL RESULTS}

The jet flow is defined as a fluid flow in which a stream of one fluid mixes with a surrounding medium, at rest or in motion. One class of jet flows is identified by the fact that the motion of the jet is induced primarily by buoyancy forces. A common example is a hot gas exhaust rising in the atmosphere (plume), as distinct from the momentum jets, or simply jets, as defined above.

For the case of hot water inlet in solar systems storage tanks, the jet is caused by both buoyancy and momentum forces, (Shah, L. J., Furbo, 2003). So, if the difference between temperatures of the inlet jet and surrounding medium is great, the velocity of the plume inside the tank increases and can achieve the turbulent regimen. But for the temperature levels and dimensions analyzed in the present work, the flow remains always laminar.

\section{A. Uniform Initial Temperature Field}


By numerical simulation, it was studied the influence of mass flow rate on the stratification profile. Initially, a uniform temperature field was considered, and investigated the influence of mass flow rate on stratification of temperature profile. The initial temperature field was uniform, with $30^{\circ} \mathrm{C}$, and the inlet jet temperature was made $10^{\circ} \mathrm{C}$ above the outlet jet, so that, for this uniform initial temperature field, the inlet jet temperature remains constant in $40^{\circ} \mathrm{C}$ during the simulation time.

Figure 2 shows the temperature profiles after intake of 4 and 8 liters of hot water, to mass flow rate of $0.5,1.0$ and 2.0 liters per minute.

These results show that, for the studied mass flow rates, the increase of inlet jet velocity don't modifies significantly the thermal stratification profile. So, for this configuration, the usual 0.5 liters per minute found in solar systems can be increased to 2.0 without major damage on stratification. It must be mentioned that the diameters of inlet and outlet jets have a diameter of $3 / 4$ ", so that, for these mass flow rate, the flows are laminar.

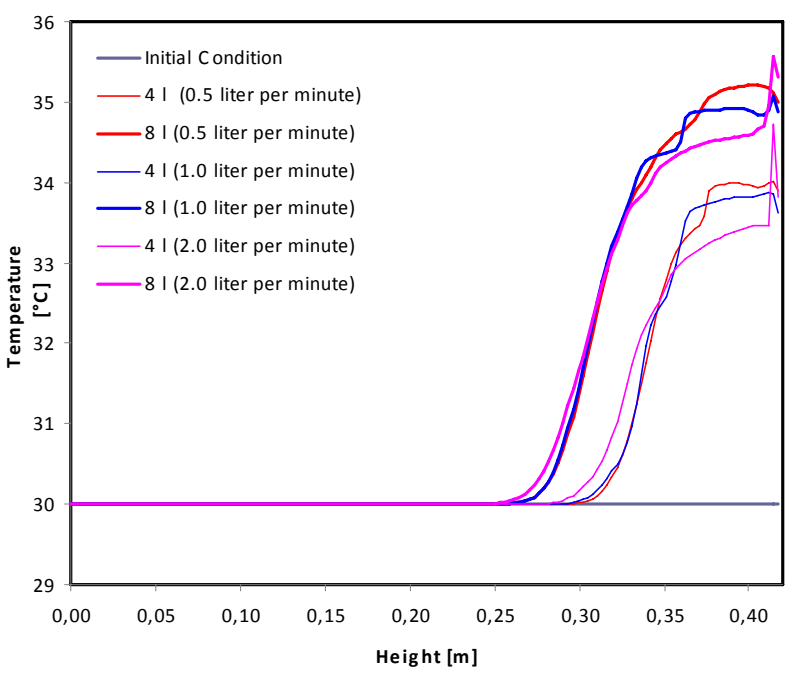

Figure 2. Stratified temperature profile obtained to mass flow rate of 0.5, 1.0 and 2.0 liters per minute, and uniform initial field.

\section{B. Stratified initial temperature field}

In this case, it was considered an initial temperature profile which correspond a typical stratified profile found in solar systems storage tanks, as shown in Fig. 3.

Due the fact that initial temperatures profile is stratified, the outlet jet temperature changes during the water circulation process, so, the inlet jet temperature, defined as $10^{\circ} \mathrm{C}$ above the transient outlet jet temperature, also changes during this process.

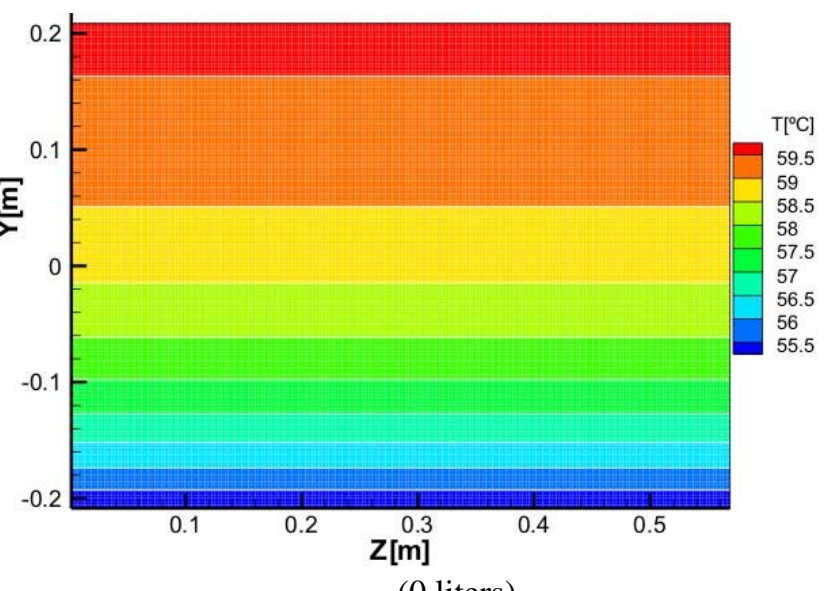

(0 liters)

Figure 3. Initial stratified temperature field, corresponding to 0 liters intake.

Figure 4 shows the temperature and velocity fields after intake of 8 liters of hot water.

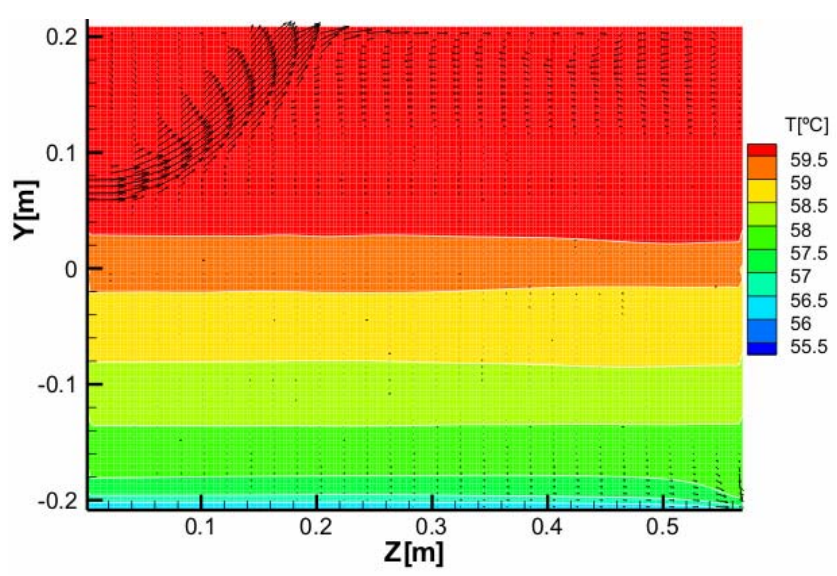

(8 liters)

Figure 4. Temperature and velocity fields after intake of 8 liters of hot water, $10^{\circ} \mathrm{C}$ above the outlet jet temperature.

In this figure, the number of vectors plotted in z-direction is decreased, for best visualization. The ascendant plume caused by buoyancy force can be observed, including the entrainment of the surrounding fluid.

For this initially stratified field, the inlet boundary condition is a transient coupled function of previous solution. Due this fact, it is interesting to investigate the temperature and velocity fields near the outlet jet.

Figure 5 shows again that, for the range of studied mass flow rate, do not occurs significant change in temperature profiles, so one can conclude that in solar energy systems the operational mass flow rate can be increased without damage on stratification profile. 


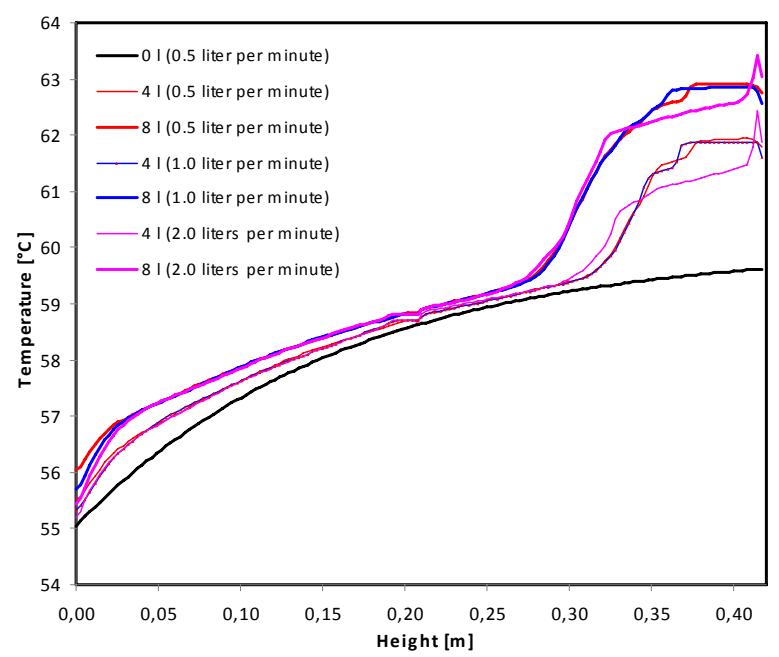

Figure 5. Temperature profiles obtained for mass flow rate of $0.5,1.0$ and 2.0 liters per minute, to stratified initial field.

Figure 6 shows a new cut view of temperature and velocity fields, in the vertical plane, while Fig. 7 shows a zoom view of the bottom left corner.

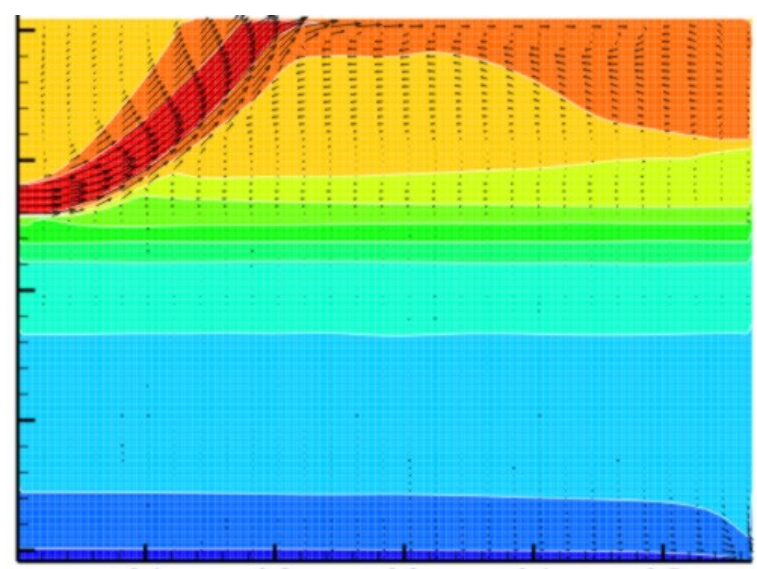

Figure 6. Global view of temperature and velocity fields for the initially stratified temperature field.

Analyzing the Fig. 6, it can be verified that the outlet jet promotes a sufficient entrainment to include a hot water stream from the higher regions. For solar systems, the optimal performance is achieved when the outlet jet leaves the tank at lowest temperature possible. So, an improvement can be proposed in order to avoid these phenomena: the introduction of some device like a long perforated pipe, for example, can be tested to remove water only from the bottom of the tank.

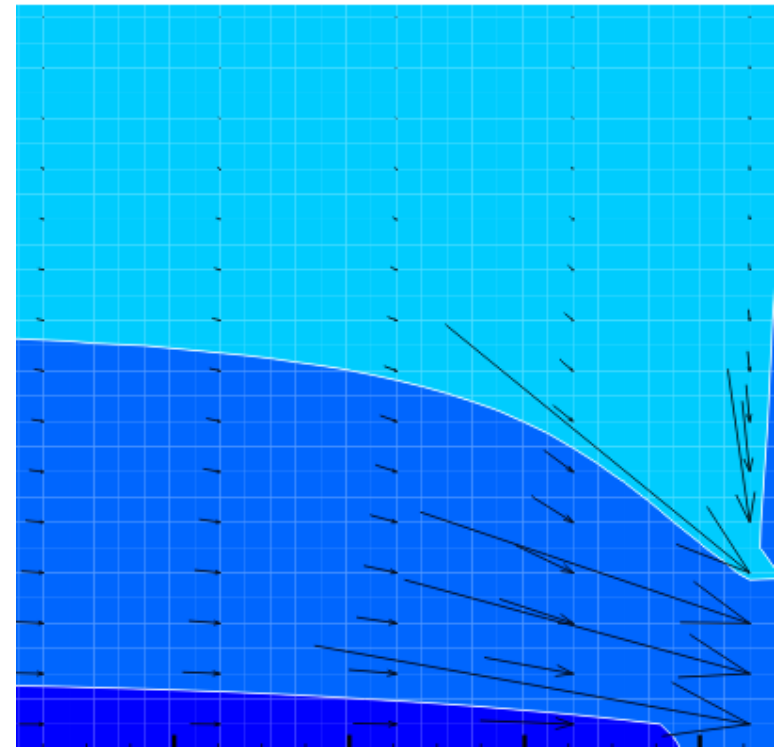

(8 liters)

Figure 7. Zoom view in the bottom of the tank, near the outlet jet.

Finally, Figs. 8, 9, 10, 11, 12 and 13 show views of temperature field inside the tank, for different times of the simulation, where it was prescribed a mass flow rate of 1.0 liters per minute, with inlet temperature of $10^{\circ} \mathrm{C}$ above the transient outlet jet temperature, as previously mentioned.

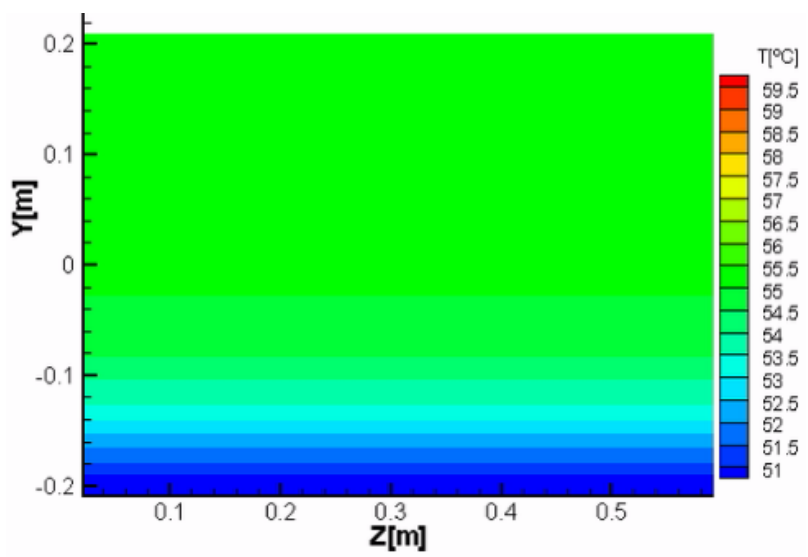

Figure 8. 2D view of initial temperature field: $0 \mathrm{~min}$. 


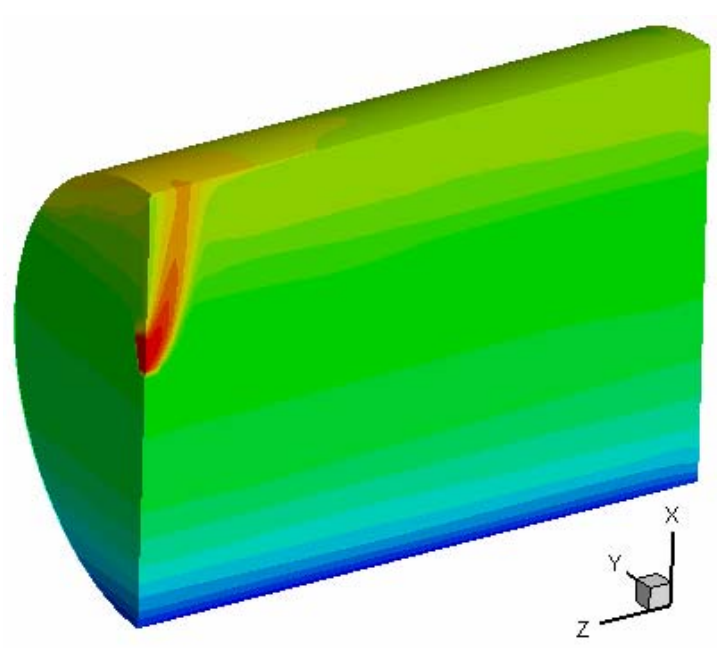

Figure 9. View of transient temperature field after 5 min, 1.0 liters per minute.

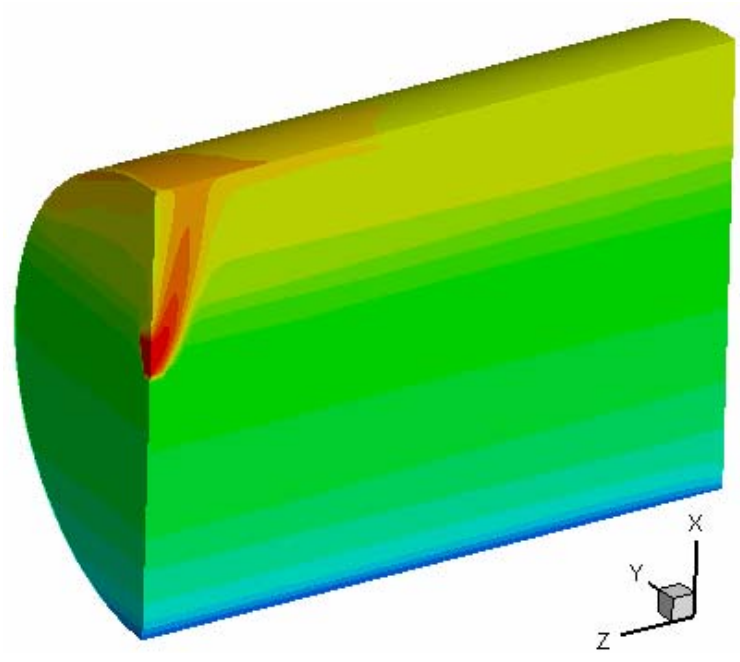

Figure 10. View of transient temperature field after $10 \mathrm{~min}$.

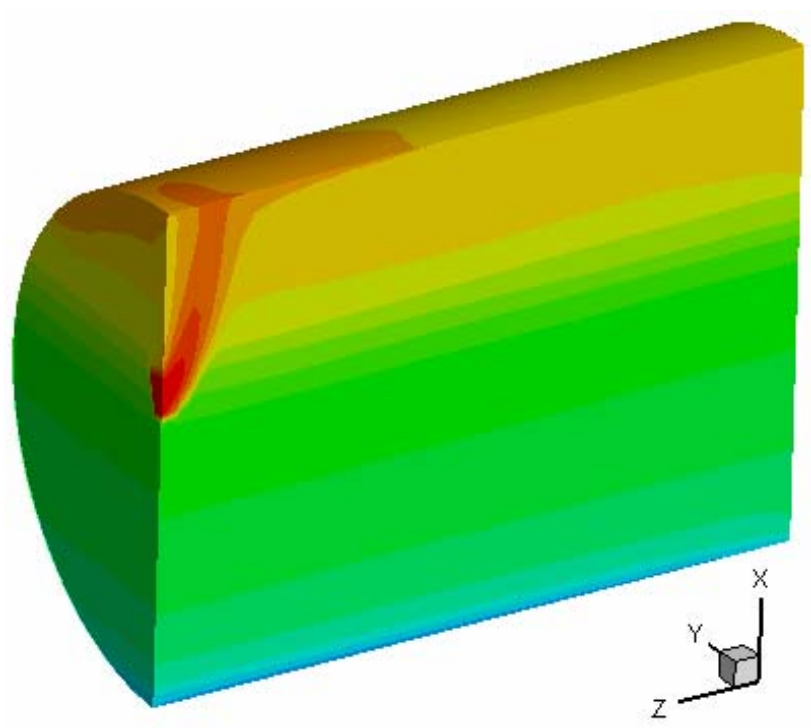

Figure 11. View of transient temperature field after $15 \mathrm{~min}$.

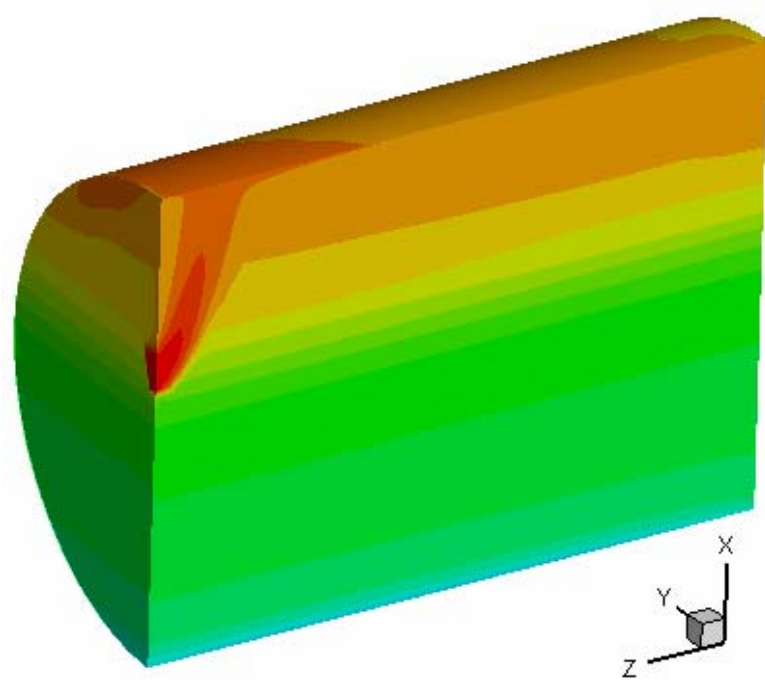

Figure 12. View of transient temperature field after $20 \mathrm{~min}$.

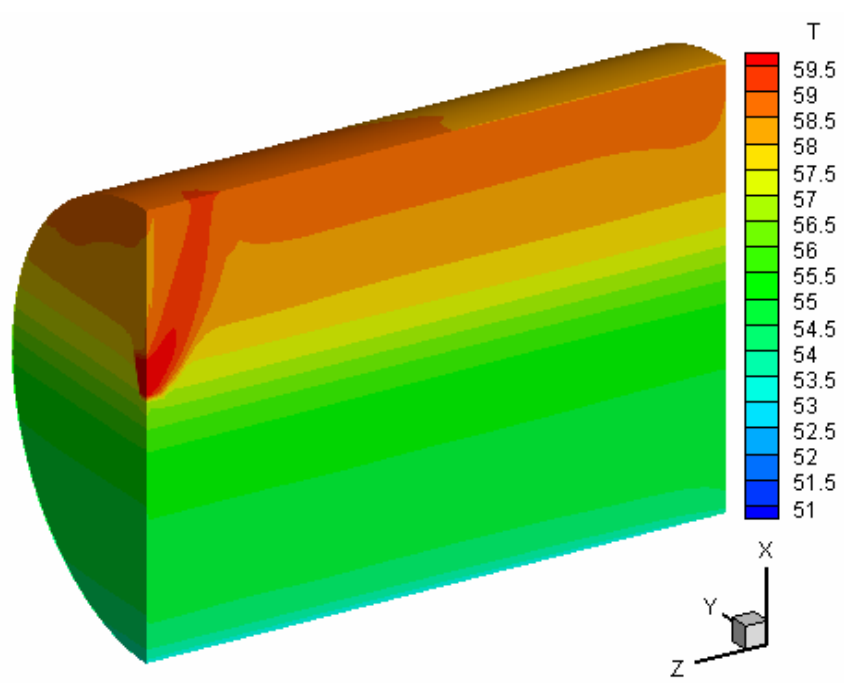

Figure 13. View of transient temperature field after $25 \mathrm{~min}$.

Figures 8, 9, 10, 11, 12 and 13 shows the transient tridimensional temperature field, where the perturbation caused due the inlet jet can be analysed. The inlet jet after intake in the tank leads an arising plume, which travels to the top of the tank, due buoyancy forces. The initial stratified temperature field changes, forming a new stratification layer in the top of the tank. The isothermal surfaces are practically horizontal, except near the position of inlet jet.

Furthermore, as can be seen, the temperature of the plume decreases in the vertical direction, due the mixture and hear transfer with the water around the plume. It shows that an optimal position of the inlet jet must be investigated, in order to minimize this mixture and obtain a greater thermal stratification. 


\section{CONCLUSIONS}

In this work, an academic tridimensional transient computational code was used to solve the problem of mixed convection in a thermal storage tank using the Finite Volumes Method. It was verified that this code is suitable to determine the velocity and temperature fields inside the cylindrical horizontal tank.

The investigations considering the thermal tank interconnected to solar collectors, with inlet jet temperature higher than that found in surrounding, showed that for the laminar mass flow rate in the range of $0.5-2.0$ liters per minute the thermal stratification profile is quasi totally preserved, so that, the usual 0.5 liter per minute can be increased without damage to thermal stratification.

In the future, the influence of the inlet jet velocity, with constant mass flow rate, will be investigated, in order to describe the influence of this parameter on thermal stratification.

\section{ACKNOWLEDGEMENTS}

The authors are grateful to $\mathrm{CNPq}$ for the research grants 300386/80-0 and 302503/2009-9.

\section{REFERENCES}

Alizadeh, S., An Experimental and Numerical Study of Thermal Stratification in a Horizontal Cylindrical Solar Storage Tank, Solar Energy, 1999, Vol. 66, pp. 409-421.

Consul, R., Rodrigues, I., Perez-Segarra, C. D., and Soria, M., Virtual Prototyping of Storage Tanks by Means of Three-Dimensional CFD and Heat Transfer Numerical Simulation, Solar Energy, 2004, Vol. 77, pp. 179-191.

Eames, P. C., and Norton, B., 1998, The Effect of Tank Geometry on Thermally Stratified Sensible Heat Storage Subject to Low Reynolds Number Flow, Int. J. Heat Mass Transfer, Vol. 41, No. 14, pp. 2131-2142.

Oliveski R. C., Vielmo H. A., and Krenzinger, A., 2003, Cooling of Cylindrical Vertical Tanks Submitted to Natural Internal Convection, International Journal of Heat and Mass Transfer, Vol. 46, pp 2015-2026.

Oliveski R. C., Vielmo H. A., and Krenzinger, A., 2003, Comparison Between Models for the Simulation of Hot Water Storage Tanks, Solar Energy, Vol. 75, Issue 2, pp. 121-134.

Savicki, Darci Luiz, 2007, Tridimensional Numerical Analysis and Experimental Investigation of the Thermal and Hydrodynamic Behaviors of Cylindrical Storage Tanks. UFRGS - Mechanical Engineering Graduate Program, Doctoral thesis.

Shah, L. J., and Furbo, S., 2003, Entrance Effects in Solar Storage Tanks, Solar Energy, Vol. 75, pp 337-348. 